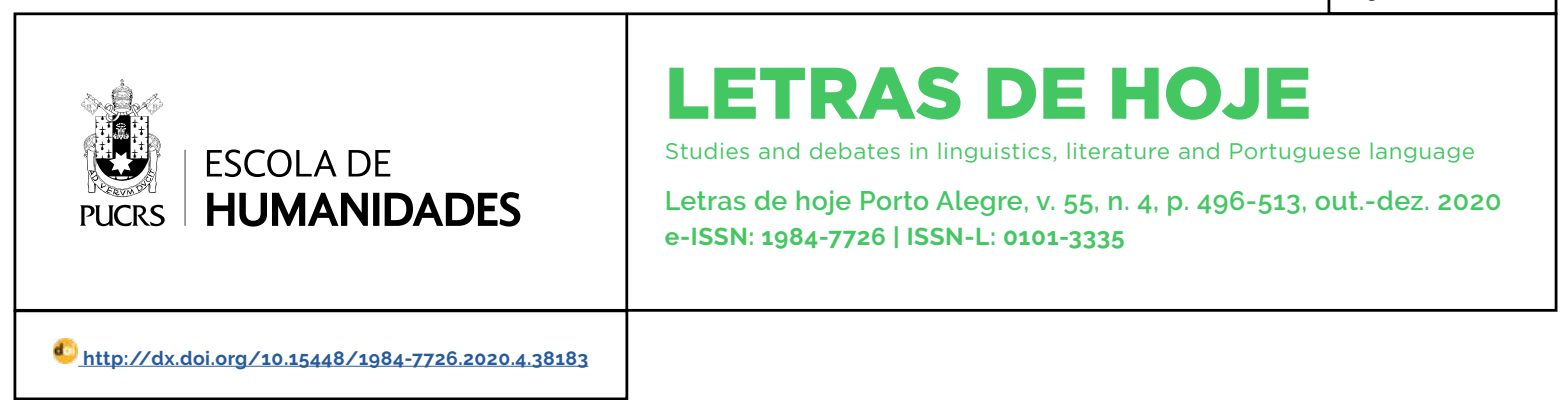

PORTUGUÊS COMO LÍNGUA ADICIONAL: LINGUISTICA E TRADUÇÃO

\title{
Tecnologias Digitais Móveis e o ensino de Língua Portuguesa para estrangeiros
}

\author{
Mobile technologies and Brazilian Portuguese teaching for foreigners \\ Tecnologías digitales móviles y enseñanza de la lengua portuguesa a extranjeros
}

\author{
Josiane Brunetti Cani ${ }^{1}$ \\ orcid.org/0000-0001-6560-484X \\ josicani@gmail.com
}

Enviado em: 17/5/2020

Aprovado em: $4 / 12 / 2020$

Publicado em: 09/02/2021
Resumo: A multiplicidade de recursos oferecidos pela internet, ampliando os serviços móveis, fez surgir a modalidade de ensino mobile learning. Por meio dessa estratégia, aplicativos (apps) instalados em aparelhos móveis utilizam tecnologias digitais de informação e comunicação para promover o ensino-aprendizagem de idiomas. A fim de compreender como ocorre esse processo, este estudo analisa três apps voltados ao ensino da língua portuguesa como segunda língua: Duolingo, Babbel e Busuu. Com base nos estudos da gamificação e aprendizagem de linguas por computador, os apps são classificados segundo quatro paradigmas, fundamentados no destaque (i) a abordagens da linguagem; (ii) ao conteúdo apresentado, como leitura, produção de textos, vocabulário, tópicos gramaticais, tarefas orais e pronúncia; e (iii) ao emprego de imagens para representar vocabulário e situações diárias. A análise dos dados permitiu compreender que, embora predomine uma estrutura behaviorista, trabalhando a lingua de forma fragmentada, como objeto de estudo e não como forma de comunicação e interação social, os três aplicativos apresentam um sistema bem planejado em termos de gamificação. Conclui-se que essas ferramentas não se apresentem como protagonistas ao ensino da lingua portuguesa para estrangeiros, mas, usadas como suporte, contribuem para a aprendizagem.

Palavras-chave: Aprendizagem de linguas por computador (CALL). Aplicativos móveis. Português como segunda língua.

Abstract: The multiplicity of resources offered by the Internet, expanding mobile services, led to the emergence of mobile learning. Through this strategy, applications installed on mobile devices use digital information and communication technologies to promote language teaching-learning. In order to understand how this process occurs, this study analyzes three apps aimed at teaching Portuguese as a second language: Duolingo, Babbel and Busuu. Based on studies of gamification and language learning by computer, apps are classified according to four paradigms, based on the highlight (i) language approaches; (ii) the content presented, such as reading, text production, vocabulary, grammatical topics, oral tasks and pronunciation; and (iii) the use of images to represent vocabulary and daily situations. Data analysis allowed us to understand that, although a behaviorist structure predominates, working the language in a fragmented way, as an object of study and not as a form of communication and social interaction, the three applications present a well-planned system in terms of gamification. It has concluded that these tools do not present themselves as protagonists to the teaching of the Portuguese language to foreigners, but, used as support, contribute to learning. Keywords: Computer language learning (CALL). Mobile apps. Brazilian Portuguese as foreign language.

Resumen: La multiplicidad de recursos que ofrece Internet, la expansión de los servicios móviles, condujo a la aparición del aprendizaje móvil. A través de esta estrategia, las aplicaciones instaladas en dispositivos móviles utilizan tecnologias digitales de la información y la comunicación para promover la enseñanza-aprendizaje de idiomas. Para entender cómo se produce este proceso, este estudio analiza 
tres aplicaciones destinadas a enseñar portugués como segunda lengua: Duolingo, Babbel y Busuu. Basados en estudios de gamificación y aprendizaje de idiomas por computadora, las aplicaciones se clasifican de acuerdo con cuatro paradigmas, basados en los enfoques de idiomas destacados (i); (ii) el contenido presentado, como lectura, producción de texto, vocabulario, temas gramaticales, tareas orales y pronunciación; y (iii) el uso de imágenes para representar vocabulario y situaciones cotidianas. El análisis de datos nos permitió entender que, aunque predomina una estructura conductista, trabajando el lenguaje de forma fragmentada, como objeto de estudio y no como una forma de comunicación e interacción social, las tres aplicaciones presentan un sistema bien planificado en términos de gamificación. Se concluye que estas herramientas no se presentan como protagonistas de la enseñanza de la lengua portuguesa a los extranjeros, sino que, utilizadas como apoyo, contribuyen al aprendizaje.

Palabras clave: Aprendizaje de idiomas por ordenador (CALL). Aplicaciones móviles. Portugués como segunda lengua.

\section{Introdução}

O processo moderno de expansão econômica, política e cultural tem importantes marcos em várias épocas e cenários, como na epopeia das grandes navegações, que permitiram ao homem se locomover com mais rapidez, propagando o mercantilismo; ou na Terceira Revolução Industrial, em meados do século $X X$, que transformou a comunicação no mundo todo.

Em todos esses cenários, povos de diferentes paises e continentes estabeleceram conexões em um fluxo que contribuiu para a globalização. O século XXI consolida essa crescente cooperação entre países, que se organizam em blocos com interesses mútuos, objetivando não apenas garantir o crescimento econômico, mas também relações sociais, educacionais e políticas.

Nesse âmbito da cooperação, o Brasil uniu-se a acordos intergovernamentais (Brics, Mercosul e Unasul)² objetivando dinamizar e intensificar sua economia mediante a globalização. Segundo Oliveira (2010, p. 24), a sociedade atual, conhecida como "sociedade do conhecimento", "a bidirecionalidade da relação entre produção e consumo, entre oferta e demanda", baseia-se na comuni- cação, ou seja, a língua é o centro de acordos transnacionais. Portanto, a falta de compreensão entre povos de diferentes idiomas, muitas vezes, influencia a escolha de parceiros e impede a expansão da integração (FIDRMUC; FIDRMUC, 2016).

Desse modo, a relação entre nações faz surgir demandas linguísticas. É comum encontrar, em diversos paises, cidadãos bilingues ou fluentes em mais de dois idiomas, prestando serviços a bares, restaurantes e lojas, dentre outros estabelecimentos, além das relações empresariais.

A lingua portuguesa é importante nesse cenário, dado o crescente número de acordos firmados pelo Brasil. Prova disso é o aumento da procura pelo Certificado de Proficiência em Língua Portuguesa para Estrangeiros (Celpe-Bras), criado em 1998.

Nesse contexto de interações, a internet se mostra cheia de oportunidades para o ensino-aprendizagem de línguas. Bancos de aulas, sites, portais, revistas e jornais do mundo inteiro, conjugando diferentes linguagens - como imagens, áudio e texto - oferecem a possibilidade de aquisição de uma segunda língua de forma criativa, prazerosa e interativa. Esses ambientes cognitivos oferecidos pelo mundo digital podem criar experiências em que "pensamos, aprendemos e recordamos, movendo nosso pensamento através das palavras, imagens e sons, fazendo intervalos para interpretar, analisar e explorar as informações em nossa volta" (PAIVA, 2001, p. 97).

Entre inúmeras formas de aprendizagem de uma segunda língua, destacam-se os softwares-aplicativos, ou simplesmente aplicativos (apps), ferramentas desenhadas para realizar tarefas e trabalhos específicos no computador. Os apps têm ganhado espaço à medida que as tecnologias digitais expandem as relações pessoais, sociais, educacionais e profissionais, baseando-se em tendências metodológicas que associam o prazer das tecnologias digitais ao ensino. Nesse cenário, surgem aplicativos móveis (softwares desenvolvidos especificamente para smartphones)

\footnotetext{
2 Brics: agrupamento político de cooperação formado por Brasil, Rússia, İndia, China e África do Sul. Mercosul: Mercado Comum do Sul, iniciativa de integração dos países da América do Sul, formado por Brasil, Argentina, Paraguai e Uruguai. Também fazem parte do Mercosul, como países associados: Chile, Colômbia, Equador, Peru, Guiana e Suriname. Unasul: União das Nações Sul-Americanas, formada por Argentina, Bolivia, Brasil, Chile, Colômbia, Equador, Guiana, Paraguai, Peru, Suriname, Uruguai e Venezuela. Tem como objetivo geral a integração social, cultural, econômica e política dos paises.
} 
que permitem a aprendizagem de linguas para além da sala de aula tradicional, seja a de escolas regulares ou de cursos específicos de lingua.

Aplicativos móveis têm sido uma ferramenta importante para o ensino de idiomas mediado pelo computer-assisted language learning (CALL). Assim, é importante refletir sobre como esses instrumentos buscam desenvolver competências lexicais, sintáticas, semânticas e, principalmente, pragmáticas. O presente estudo analisa o ensino de língua portuguesa em três desses apps, todos gratuitos e disponíveis em iOS e Android: Duolingo, Babbel e Busuu.

Os aplicativos analisados são classificados de acordo com três paradigmas educacionais. No primeiro, a abordagem que destaca: (a) a linguagem prescritiva e normativa (lingua compreendida como sistema homogêneo e estático); (b) a linguagem como instrumento de comunicação (língua entendida como código; e (c) a linguagem como meio de interação (língua como forma de interação humana em práticas sociais e discursivas). O segundo paradigma enfatiza o conteúdo abordado, como leitura, produção de texto, vocabulário, tópicos gramaticais e tarefas orais e de pronúncia. Por fim, o terceiro paradigma destaca uma análise dos recursos visuais (imagens) usados nos aplicativos como suporte ao ensino de vocabulário, também atrelado a situações diárias.

\section{Abordagens da linguagem e Computer-Assisted Language Learning}

O ensino de linguas estrangeiras se organiza por meio de um conjunto de concepções teóricas e práticas que visam à aquisição do idioma pelo usuário. São vários os construtos teóricos que fundamentam esse tipo de ensino-aprendizagem, no entanto abordamos três abordagens que se destacam: a behaviorista, a comunicativa e a integrativa (WARSCHAUER; HEALEY, 1998). Os estudos dessas abordagens, por sua vez, subdividem-se em outras áreas, mais especificas, como a linguística aplicada e, principalmente, a second language acquisition (SLA) (JOHNSON, 2004; KRASHEN, 1985; MITCHELL; MARSDEN; MYLES, 2013).

No início da SLA, nos anos 1960 e 1970, a for- ma de ensino de língua estrangeira foi inspirada nos estudos behavioristas, que se apoiavam na aprendizagem pelo condicionamento (BLAKE, 2013; GRUBA, 2004; WARSCHAUER, 1996; WARSCHAUER; HEALEY, 1998), ou seja, "a lingua era vista como um hábito condicionado que se adquiria através de um processo mecânico de estímulos e respostas" (LEFFA, 1988, p. 219). Assim, a apresentação de unidades isoladas de conteúdos linguísticos, com exercícios de repetição orientando a representação da fala, era percebida como suficiente para tornar-se uma pessoa proficiente em uma língua estrangeira (WARSCHAUER, 1996).

Entretanto, a visão comunicativa desafiou o behaviorismo e passou a fundamentar a teoria da SLA, destacando as funções da linguagem e permitindo o desenvolvimento de programas baseados em leitura, jogos e reescrita de textos (HEALEY; JOHNSON, 1995). A segunda etapa do ensino da SLA, nas décadas de 1970 e 1980, surgiu com teóricos que defendiam uma comunicação autêntica. Almeida Filho (1993, p. 36) assevera que os métodos comunicativos para a aprendizagem de línguas mudaram os paradigmas da prática dos professores, pois esse tipo de ensino estrutura as vivências do aprender por meio de "atividades relevantes/tarefas de real interesse e/ou necessidade do aluno para que ele se capacite a usar a língua-alvo para realizar ações de verdade na interação com outros falantes-usuários dessa língua".

A terceira teoria proposta por estudiosos, o ensino da SLA integrativo, baseou-se na evolução de dois grandes aliados: o computador multimídia e a internet. O primeiro proporcionou fácil acesso a uma variedade de mídias, como som, animação, vídeos e estilos gráficos, e o segundo possibilitou a interconectividade, que estimula a aprendizagem por intermédia das tecnologias digitais. Conforme aponta Warschauer (1996), a hipermídia diferencia o ensino-aprendizagem de língua pela combinação de audição e visão, representando o mundo real, e pelo desenvolvimento de habilidades linguísticas a partir da articulação de leitura, escrita, fala e escuta em uma única atividade. Além disso, os alunos podem ter controle sobre a própria aprendizagem, definindo caminhos e ritmos a serem seguidos, bem como associar um 
foco principal com objetivos secundários.

Nesse cenário, são várias teorias que procuram esclarecer como ocorre a produção da fala em uma lingua estrangeira, desde o estado inicial até formas de expressão e de interação social (CORREA, 1999). A teoria da aculturação, proposta por Schumann (1978), argumenta que a aquisição de uma segunda língua é determinada por variáveis afetivas e sociais. A hipótese do input, proposta por Krashen (1985 apud PAIVA, 2014), destaca que ambientes informais, tanto quanto formais, contribuem para a proficiência linguística. Já a hipótese da interação afirma que a aquisição se dá por meio de esforços comunicativos, e não partindo da gramática para o discurso $(\mathrm{HATCH}$, 1978; LONG, 1996; PAIVA, 2014).

No século $X X I$, a praticidade proporcionada pelas tecnologias digitais permite que nos conectemos em diferentes lugares e contextos a fim de desenvolver a aprendizagem. Se as primeiras formas de ensino a distância se utilizavam, basicamente, de mídias impressas, televisão e rádio, hoje a internet ampliou essa infraestrutura com plataformas e softwares de acesso síncrono e assíncrono entre usuários e ferramentas tecnológicas. Esses instrumentos e seus métodos educacionais hoje são discutidos por meio do conceito de aprendizagem móvel (m-learning) (SACCOL; SCHLEMMER; BARBOSA, 2011).

Embora ainda em processo de consolidação, o conceito de $m$-learning tem ganhado cada vez mais importância (COSTA, 2018). Traxler e Kukulska-Hulme (2005, p. 42) observam que o m-learning é "espontâneo, portátil, pessoal, situado; pode ser informal, discreto, onipresente ou desordenado, e nos leva muito mais perto da ideia de 'a qualquer hora, em qualquer lugar'"3. Os autores destacam que "dispositivos móveis, pessoais e sem fio estão transformando radicalmente as noções sociais de discurso e conhecimento, e são responsáveis por novas formas de arte, emprego, linguagem, comércio, privação e criminalidade, bem como aprendizado" (TRAXLER, 2007, p. 2). ${ }^{4}$

Sharma et al. (2006) destacam que a adoção do m-learning desenvolve papéis educativos, conteúdos curriculares e práticas em sala de aula. Considerando uma aprendizagem eclética, os autores chamam atenção para as vantagens dos dispositivos móveis como meio de comunicação ubiqua e com interfaces inteligentes. Eles observam que a exploração dessas tecnologias facilita, melhora e amplia o alcance do ensino-aprendizagem.

Enfatizando o protagonismo do aluno no processo educacional, Wang, Wu e Wang (2009) também consideram o m-learning uma estratégia flexivel, colaborativa e personalizada. Cheon et al. (2012, p. 1055) salientam a flexibilidade de tempo e localização e três caracteristicas básicas:

(a) portabilidade: dispositivos móveis podem ser levados para locais diferentes;

(b) conectividade instantânea: dispositivos móveis podem ser usados para acessar uma variedade de informações a qualquer hora e em qualquer lugar; e

(c) sensibilidade ao contexto: dispositivos móveis podem ser usados para encontrar e coletar dados reais ou simulados. ${ }^{5}$

Os autores destacam que essas características do $m$-learning podem proporcionar uma experiência única de aprendizado a partir de recursos como câmera e aplicativos, que geram, organizam e manipulam informações para o ensino-aprendizagem. Para esses pesquisadores, embora muitos fatores sociais, culturais e organizacionais ainda desafiem a aplicação do m-learning, essas ferramentas já permitem a troca de informações entre professores e alunos, tarefas administrativas escolares como verificação de frequência e progresso de aprendizagem e aulas on-line e interativas, além de outras possibilidades.

Nesse cenário, as tecnologias móveis estão em constante evolução, e isso inclui smartphones, tablets, leitores de livros digitais, consoles

\footnotetext{
3 Tradução nossa. Original: "[...] spontaneous, portable, personal, situated; it can be informal, unobtrusive, ubiquitous and disruptive. It takes us much nearer to 'anytime, anywhere'".

4 Tradução nossa. Original: "[...] that mobile, personal, and wireless devices are now radically transforming societal notions of discourse and knowledge, and are responsible for new forms of art, employment, language, commerce, deprivation, and crime, as well as learning". 5 Tradução nossa. Original: "(a) portability: mobile devices can be taken to different locations, (b) instant connectivity: mobile devices can be used to access a variety of information anytime and anywhere, and (c) context sensitivity: mobile devices can be used to find and gather real or simulated data".
} 
de videogame e aparelhos de áudio portáteis - e essa lista tende a aumentar. O m-learning já é onipresente na sociedade, superando os limites da aprendizagem formal e informal (UNESCO, 2013). Historicamente, a aprendizagem formal se estabeleceu entre as paredes da sala de aula, enquanto os dispositivos móveis maximizam os ambientes de conhecimento. Vários aplicativos permitem que o usuário faça passeios virtuais por continentes, paises e cidades diferentes, aprendendo sobre geografia, história, biologia ou qualquer outra disciplina, de modo que "os aparelhos móveis podem dar significado literal ao ditado 'o mundo é uma sala de aula'" (UNESCO, 2013. p. 19). Os smartphones têm sido ferramentas de aprendizagem espontânea que rompem com os paradigmas pedagógicos tradicionais do ensino de línguas (COSTA, 2018).

\section{A internacionalização da Língua Portuguesa}

O crescente desenvolvimento tecnológico, e sobretudo a ampliação do acesso à internet, tem gerado um processo de desterritorialização ${ }^{6}$ que encurta distâncias geográficas e permite ao usuário estar em vários lugares ao mesmo tempo, como um nômade em busca de informações (LÉVY, 1996). Essa proposta abre novos espaços de interação, suscitando o desenvolvimento de habilidades ligadas às demandas de uma sociedade globalizada. Uma delas é o domínio de idiomas, necessário para os intercâmbios sociais, culturais, educacionais, politicos ou econômicos.

O principal padrão internacional para medir o domínio de uma língua é o Quadro Comum Europeu de Referência para Idiomas: Aprendizagem, Ensino e Avaliação (QCER) ${ }^{7}$, documento que apresenta diretrizes para:

\footnotetext{
$\Rightarrow$ promover o plurilinguismo e a diversificação na escolha das línguas no currículo;

$\Rightarrow$ apoiar o desenvolvimento e a demonstração do perfil plurilingue de alunos individuais;
}

\begin{abstract}
$\Rightarrow$ desenvolver e rever o conteúdo dos currículos de linguas e definir descritores positivos adaptados à idade, aos interesses e às necessidades dos alunos;

$\Rightarrow$ conceber e desenvolver livros didáticos e material didático;

$\Rightarrow$ apoiar a formação de professores e a cooperação entre professores de diferentes idiomas; $\Rightarrow$ melhorar a qualidade e o sucesso na aprendizagem, ensino e avaliação; e

$\Rightarrow$ facilitar a transparência nos testes e a comparabilidade das certificações (CONSELHO DA EUROPA, 2001).
\end{abstract}

O QCER tem como finalidade proporcionar "uma base comum para a elaboração de programas de linguas, linhas de orientação curriculares, exames, manuais etc., na Europa" (CONSELHO DA EUROPA, 2001, p. 19). Ele é utilizado em exames internacionais como referência para determinar o grau de proficiência em um idioma. O QCER descreve as competências que o aluno deve demonstrar em cada nível: A1 (Iniciante); A2 (Elementar); B1 (Intermediário); B2 (Intermediário Superior); C1 (Proficiente Avançado); e C2 (Proficiente Master). ${ }^{8}$ Em cada um desses niveis, as habilidades são divididas em seis graus de proficiência que vão do iniciante ao fluente, orientando a classificação das competências em provas de nivelamento de escolas de idiomas, processos de seleção para programas de intercâmbio e cursos de pós-graduação, entre outros (CANI; SANTIAGO, 2018).

Com base no QCER e atendendo às políticas públicas de internacionalizar o ensino do português, têm sido desenvolvidas no Brasil algumas ações, como intercâmbios para pesquisa, graduação e pós-graduação e programas de idiomas em instituições educacionais (CANI; SANTIAGO, 2018). O país tem empreendido estratégias para o ensino e propagação do Português como Língua Adicional ( $P L A)$ tanto em território nacional, investindo na proficiência de imigrantes, quanto no exterior, por meio de programas de intercâmbio e habilitação de professores para projetos de ensino, pesquisa e extensão em colaboração internacional.

Portanto, reconhece-se a importância do por-

\footnotetext{
Conceito proposto pelos filósofos Gilles Deleuze e Félix Guattari (1996).

Tradução nossa para "Common European Framework of Reference for Languages: Learning, Teaching, Assessment" (CEFR)

Ver Escala Global de niveis de referência do QCER em https://www.coe.int/en/web/common-european-framework-reference-languages/table-1-cefr-3.3-common-reference-levels-global-scale. Acesso em: 12 set. 2018
} 
tuguês em contexto global, visto que as projeções internacionais exigem articulações entre politica cultural e interesses geopolíticos. Além disso, como afirma o QCER (2018), aprender uma segunda língua é um direito de todo cidadão, e esse aprendizado facilita o desenvolvimento pessoal, cultural e profissional.

Nesse contexto, para mensurar os niveis de domínio da Lingua Portuguesa, a partir de 1990 ficou clara a necessidade de uma referência. Assim, o Ministério da Educação convocou uma comissão técnica formada por estudiosos da área de PLA para elaborar o Certificado de Proficiência em Lingua Portuguesa para Estrangeiros (Celpe-Bras).

O Celpe-Bras mensura a proficiência na lingua para desempenhar ações, não se restringindo a perspectivas textuais. O foco está em aspectos discursivos de interação, considerando o contexto, os interlocutores e seus propósitos.

O teste envolve compreensão e produção oral e escrita em práticas cotidianas, sem aferir explicitamente questões de gramática e vocabulário - embora esses fatores também sejam considerados nas tarefas desempenhadas pelos candidatos (SCARAMUCCl, 1995). A prova pode servir de base para que instituições educacionais elaborem exercicios, exames e materiais didáticos para mensurar o nivel de proficiência dos alunos (DOUGLAS, 2000; WEIGLE, 2002). Para cada nível, há o objetivo do usuário, assim como sua capacidade de uso da língua:

Intermediário - é capaz de produzir textos escritos sobre assuntos variados que, com dificuldade, podem ser reconhecidos como pertencentes a determinados gêneros discursivos, podendo não configurar adequadamente a interlocução. Os recursos lexicais e gramaticais mobilizados são limitados, podendo apresentar problemas de clareza e coesão e/ou inadequações frequentes que comprometem mais frequentemente a fluidez da leitura. É capaz de selecionar algumas informações a partir da interpretação de textos de diferentes gêneros orais e escritos, evidenciando problemas de compreensão e dificuldades no trabalho de recontextualização que podem levar ao cumprimento parcial dos propósitos dos textos produzidos. É capaz de interagir oralmente para a expressão de ideias e opiniões sobre assuntos variados. Apresenta poucas hesitações, com algumas interrupções no fluxo da conversa. Seu vocabulário pode apresentar limitações que podem comprometer o desenvolvimento da interação. Utiliza variedade limitada de estruturas, com algumas inadequações em estruturas complexas e poucas inadequações em estruturas básicas. Sua pronúncia contém inadequações e/ou interferências frequentes de outras linguas. Demonstra alguns problemas de compreensão do fluxo da fala, com necessidade frequente de repetição e/ou reestruturação ocasionada por palavras de uso frequente em nivel normal de fala.

Intermediário Superior - é capaz de produzir textos escritos de diferentes gêneros discursivos sobre assuntos variados, podendo configurar a interlocução de forma nem sempre adequada e mobilizando recursos lexicais e gramaticais nem sempre apropriados aos gêneros produzidos, podendo apresentar problemas de clareza, coesão e/ou inadequações que podem comprometer a fluidez da leitura. É capaz de recontextualizar, ainda que com equivocos, informações a partir da interpretação de textos de diferentes gêneros orais e escritos, podendo demonstrar problemas de compreensão. Inadequações podem dificultar o cumprimento dos propósitos dos textos produzidos.

É capaz de interagir oralmente para a expressão de ideias e opiniões sobre assuntos variados. Demonstra fluência, com algumas pausas e hesitações que às vezes interrompem o fluxo da conversa. Seu vocabulário é adequado, embora apresente algumas interferências de outras linguas. Apresenta algumas inadequacões no uso de estruturas complexas e poucas no uso de estruturas básicas. Sua pronúncia contém inadequações e/ou interferências de outras linguas. Demonstra alguns problemas de compreensão do fluxo natural da fala do interlocutor, com necessidade de repetição e/ou reestruturação ocasionada por palavras de uso frequente, em ritmo normal da fala.

Avançado - é capaz de produzir textos escritos claros e coesos de diferentes gêneros discursivos sobre assuntos variados, configurando a interlocução de forma adequada, utilizando recursos lexicais e gramaticais apropriados aos gêneros produzidos. É capaz de recontextualizar adequadamente informações relevantes obtidas a partir da interpretação de textos de diferentes gêneros orais e escritos, demonstrando compreensão eficiente. Inadequações pontuais podem fragilizar partes do texto, ainda que não comprometam o cumprimento dos propósitos dos textos produzidos.

É capaz de interagir oralmente com autonomia e desenvoltura para a expressão de ideias e opiniões sobre assuntos variados, contribuindo para o desenvolvimento da interação. Demonstra fluência, com poucas interrupções do fluxo natural da conversa. Seu vocabulário é amplo e adequado, com poucas interferências de outras linguas. Utiliza uma variedade ampla e adequada de estruturas, com poucas inadequações no uso de estruturas complexas e raras inadequações no uso de estruturas básicas. Sua pronúncia pode apresentar algumas inadequações e/ou interferências de outras linguas. Demonstra compreensão do fluxo natural da fala do interlocutor, com alguma necessidade de repetição e/ou reestruturação ocasionada por palavras menos frequentes e/ou por aceleração da fala. 
Avançado Superior - é capaz de produzir textos escritos claros e coesos de diferentes gêneros discursivos sobre assuntos variados, configurando a interlocução de forma adequada e consistente, utilizando recursos lexicais e gramaticais apropriados aos gêneros produzidos. É capaz de recontextualizar, com propriedade. informações relevantes obtidas a partir da interpretação de textos de diferentes gêneros orais e escritos, demonstrando compreensão eficiente e seletiva. Eventuais inadequações pontuais não comprometem o bom cumprimento dos propósitos dos textos produzidos.

É capaz de interagir oralmente com muita autonomia e desenvoltura, utilizando vocabulário amplo e adequado e variedade também ampla de estruturas para expressar ideias e opiniões sobre assuntos variados, contribuindo muito para o desenvolvimento da interação. Apresenta fluência, sem interrupções do fluxo natural da conversa, e pronúncia adequada. Demonstra compreensão do fluxo natural da fala do interlocutor, com rara necessidade de repetição e/ou reestruturação (BRASIL, 2020, p. 67-68).

Segundo Stern (1987), o foco principal do planejamento comunicativo são ações em torno de temas e tópicos que envolvam o aprendiz em uma comunicação real. Nesse contexto, o propósito do Celpe-Bras é ser um exame que dê atenção, principalmente, ao significado das mensagens, e não ao código, com uma aprendizagem natural que contribui para a autonomia da proficiência do aprendiz.

O processo de avaliação realiza-se a distância, por meio de uma plataforma on-line, na qual todos os textos escritos pelos participantes são disponibilizados em formato digital, assim como os áudios de interações face a face (BRASIL, 2020). São quatro tarefas que avaliam dimensões distintas do construto do exame pelas diferentes especificações: propósitos de compreensão e de produção, gênero, interlocução, recursos informacionais, discursivos e linguisticos.

O exame é formado por dois segmentos: parte escrita (coletiva) e parte oral (individual). A seguir, podemos observar o fluxo para avaliação das partes escrita e oral.

Figura 1 - Fluxo para atribuição de notas na Parte Escrita do Celpe-Bras

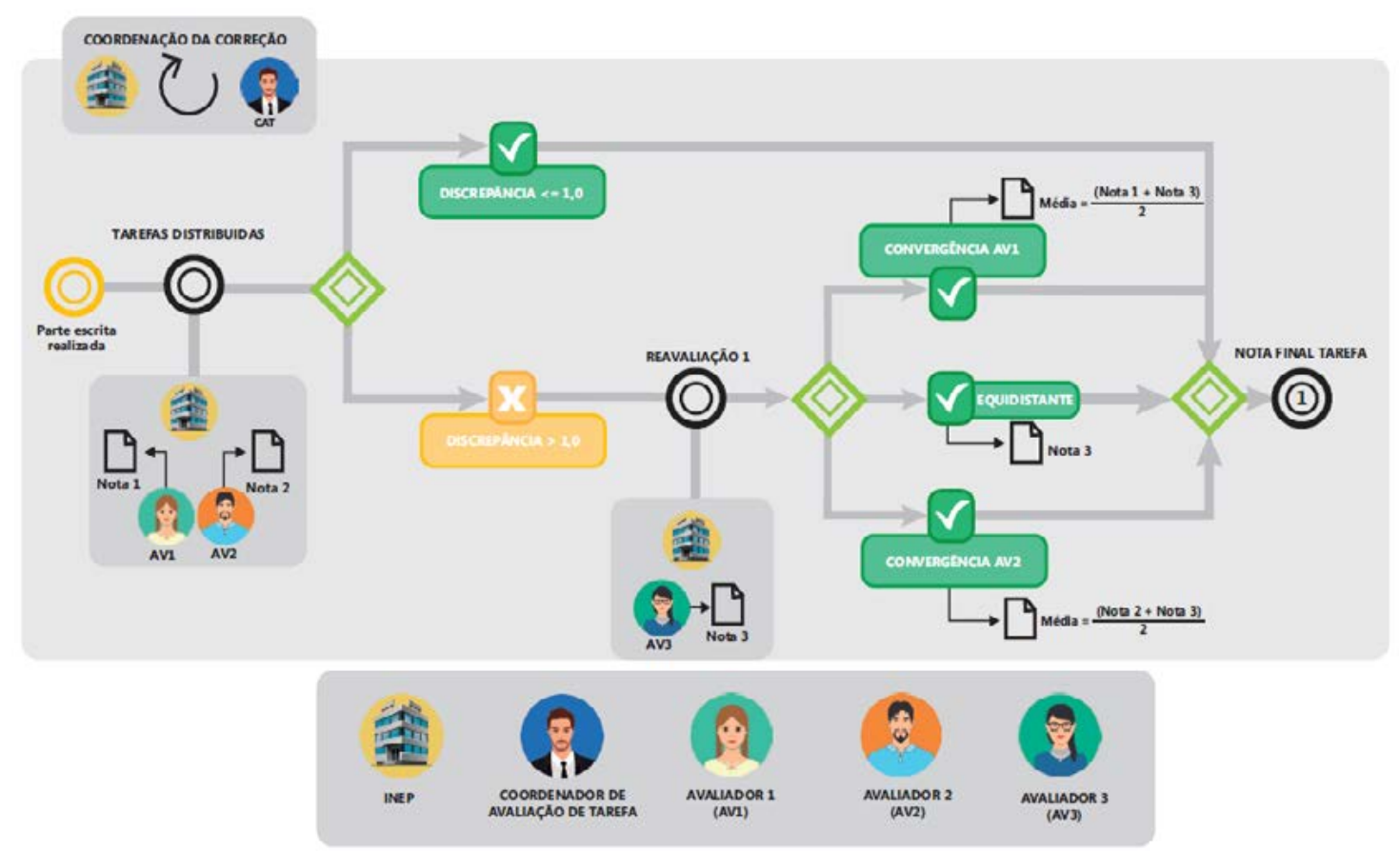

Fonte: Brasil (2020, p. 74)

As duas primeiras tarefas da Parte Escrita integram a compreensão oral e a produção escrita, enquanto as duas últimas integram a leitura e produção escrita. Isso ocorre por meio de textos multimodais, presentes na Tarefa 1 (um vídeo), na Tarefa 2 (um áudio) e, por vezes, nas Tarefas 3 ou 4 (textos escritos). São três horas de duração do exame escrito, objetivando avaliar, de forma integrada, compreensão oral e imagética, leitura e produção escrita em língua portuguesa. 
Figura 2 - Fluxo para atribuição de notas na Parte Oral do Celpe-Bras

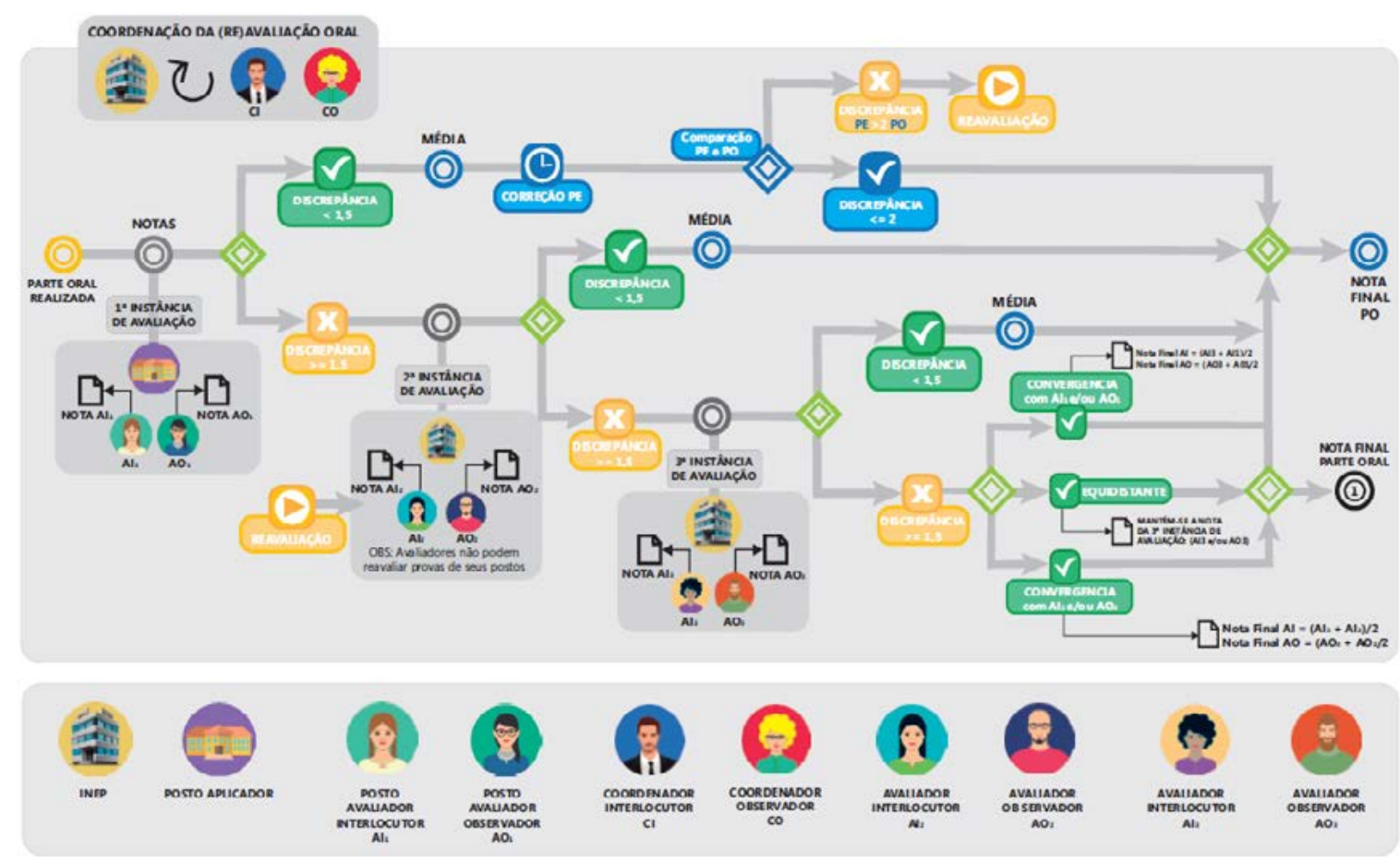

Fonte: Brasil (2020, p. 78).

A interação na Parte Oral avalia a compreensão e a produção orais. Por intermédio de elementos provocadores, textos multimodais, há o envolvimento da leitura refletindo na interatividade. Dura cerca de 20 minutos, conduzida por avaliadores também com a função de interlocutor, com um único participante por vez e na presença de outro avaliador (observador). A interação ocorre por situações de comunicação próximas às reais, simulando conversas do dia a dia. A conversa gira em torno de interesses pessoais, a partir de informações fornecidas no formulário de inscrição, e pequenos textos motivadores com imagens e textos variados publicados na imprensa brasileira (BRASIL, 2015).

Segundo a pontuação final obtida em cada uma das partes do exame, o participante será classificado em um dos quatro níveis de proficiência do Celpe-Bras demonstrados na Figura 3.

Figura 3 - Niveis de certificação por faixa de notas

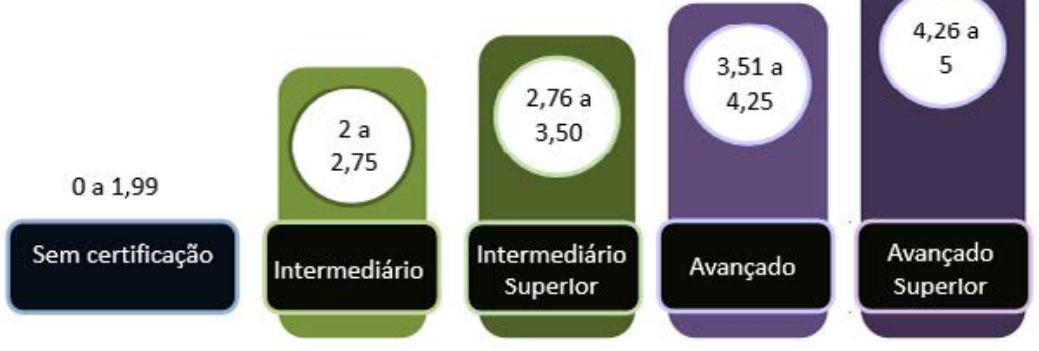

Fonte: Elaboração própria baseada em Brasil (2020, p. 79).

A Certificação de Proficiência em Língua Portuguesa ocorrerá se o participante alcançar, pelo menos, o nivel intermediário nas duas partes: escrita e oral. Caso ocorra divergências no desem- penho, prevalecerá a nota de menor resultado.

Há uma série de iniciativas que possibilitam estrangeiros a estudar a Lingua Portuguesa. Dentre elas, destacamos o Instituto de Estudos da Lingua- 
gem (IEL) da Unicamp, que apresenta, em um blog intitulado "Foca no português para estrangeiros"9, uma lista de portais e blogs instrucionais direcionados ao idioma como língua estrangeira. Há ainda o Portal do Professor de Português Lingua Estrangeira (PPPLE), plataforma on-line cujo objetivo é oferecer a professores e interessados em geral recursos e materiais para o ensino-aprendizagem do português como lingua estrangeira. O site é desenvolvido e alimentado pelos Estados-membros da Comunidade dos Países de Língua Portuguesa (CPLP): Angola, Brasil, Cabo Verde, Guiné-Bissau, Guiné Equatorial, Moçambique, Portugal, São Tomé e Príncipe e Timor-Leste. ${ }^{10}$

O interesse do presente estudo não é apontar como o Brasil tem se posicionado oficialmente para se lançar como país que investe no ensino de sua língua para os que se encontram fora do país ou que migram para cá. Nosso foco está no ensino informal de português para estrangeiros por meio de aplicativos móveis, o que nos convida a explorar as affordances de tecnologias digitais como um potencial espaço de aprendizagem. Nesse contexto, buscamos refletir se os apps concebem o estudo da língua por meio de um sistema dinâmico, empreendendo atividades reais baseadas em relações entre comunidades, indivíduos e espaços sociais e permeadas por uma interação capaz de construir significados e identidades (LARSEN-FREEMAN; CAMERON, 2008).

\section{Caminhos metodológicos}

O presente estudo, de abordagem qualitativa, analisa três aplicativos móveis, disponiveis em iOS, Android e web, que se propõem a ensinar a lingua portuguesa para estrangeiros: Duolingo, Babbel e Busuu. Importante ressaltar que não há referências nos aplicativos a respeito de uma diferenciação entre o português brasileiro e o português europeu, embora, em alguns momentos, surjam abordagens de vocábulos característicos dos paises de língua lusófona.

A seleção foi realizada por meio de pesquisa no Google, delimitada para o ano de 2019, sobre os apps para ensino de linguas mais acessados. ${ }^{11}$ Foram escolhidos, dentre essas ferramentas, as que ofertavam o ensino de português e eram gratuitas, visto que trabalhamos sob a premissa do ensino democrático.

Escolhidos os apps, partimos para a análise, embasada em três categorias:

(i) abordagens da linguagem (abordagem da língua como instrumento prescritivo e normativo ou meio de comunicação e interação predominante nos aplicativos);

(ii) conteúdo abordado (estratégias de ensino da língua, ou seja, atividades de leitura e produção textual, vocabulário, tópicos gramaticais, tarefas orais, de pronúncia etc.); e

(iii) linguagem visual (ilustração de vocabulário e de situações diárias que representem adequadamente a cultura do país).

\section{Análise dos aplicativos}

Os aplicativos escolhidos são softwares que permitem o ensino de idiomas por meio de atividades gratuitas ou pagas, prometendo auxiliar seus usuários desde o aprendizado inicial até niveis mais avançados.

\subsection{Apresentação dos aplicativos \\ 5.1.1 Duolingo}

O Duolingo é uma plataforma de ensino, desenvolvida por Luis Von Ahn, lançada para o público em 2012. Segundo dados da Google Play Store, em 2014 a ferramenta foi a mais procurada por quem desejava aprender outra língua, registrando 100 milhões de usuários no mundo todo (PROTALINSKI, 2015).

\footnotetext{
Disponivel em: http://wwwz.iel.unicamp.br/matilde/2017/06/portais-e-blogs/. Acesso em: 15 ago. 2019.

Disponivel em: http://www.ppple.org/o-portal. Acesso em: 15 maio 2020.

Os três primeiros resultados da pesquisa: https://www.apptuts.com.br/tutorial/android/sites-aplicativos-para-estudar-idiomas/. https://www.correio24horas.com.br/noticia/nid/conheca-10-aplicativos-gratuitos-para-aprender-idiomas/ e http://noticias.universia com.br/destaque/noticia/2017/09/18/1155792/ aplicativos-ensinam-idiomas-smartphone.html. Acesso em: 16 mar. 2019. Todos apontavam os apps Duolingo, Babbel e Busuu como referência para o ensino de línguas.
} 
O app oferece a aprendizagem de espanhol, francês, alemão, italiano, português, russo, japonês, holandês, sueco, irlandês, turco, norueguês, coreano, dinamarquês, polonês, chinês, hebraico, grego, vietnamita, esperanto, galês, ucraniano, húngaro (versão beta), romeno, suaili, alto valiriano e tcheco. Porém, se a primeira língua do usuário for o português, há apenas seis cursos disponiveis: inglês, espanhol, francês, alemão, italiano e esperanto.

As aulas do Duolingo são projetadas como em um jogo no qual o usuário ganha pontos a cada resposta correta, recebendo moedas chamadas "lingot", que podem ser usadas para comprar itens na loja virtual do app. Pela facilidade de acesso por meio de vários dispositivos, a aprendizagem gamificada e a diversidade de exercícios tem despertado interesse não só em quem deseja aprender um novo idioma de modo informal, mas também em professores e alunos que estudam idiomas formalmente (MOTA et al., 2016; MUNDAY, 2016).

\subsubsection{Babbel}

Babbel é um software de aprendizagem de línguas com mais de 1 milhão de assinantes ativos $^{12}$, criado em 2007, por Markus Witte. Para acessar o aplicativo, é preciso se registrar, o que pode ser feito por meio de contas no Facebook e Gmail ou no próprio site. A ferramenta não funciona exclusivamente pelo celular, e alguns serviços, como certificados e cursos de escrita, estão disponiveis apenas pelo computador.

O app disponibiliza aulas de 14 idiomas (holandês, dinamarquês, inglês, francês, alemão, indonésio, italiano, norueguês, polaco, português, russo, sueco, espanhol e turco), com teste de nivelamento, reconhecimento de fala (recurso opcional) e conteúdo dividido em pequenos blocos para serem usados no dia a dia.

\subsubsection{Busul}

O Busuu é uma rede social de aprendizagem de línguas criada em 2008, por Bernhard Niesner e Adrian Hilti. O site disponibiliza espaços de interação para doze idiomas: inglês, espanhol, português, alemão, francês, italiano, russo, polo- nês, mandarim, japonês, árabe e turco. O usuário pode se inscrever gratuitamente para alguns recursos ou, como ocorre com o app Babbel, é preciso fazer uma assinatura para acessar aulas avançadas de gramática off-line, treinador de vocabulário adaptativo e certificado.

A partir de 2015, a parceria com a McGraw-Hill Education, uma das maiores e mais respeitadas empresas de educação do mundo, permitiu ao app criar uma certificação oficial para que os alunos validem sua aprendizagem de idiomas. Os testes oferecidos medem a proficiência dos seguintes niveis do QCER: A1, A2, B1 e B2.

\subsection{Análise dos apps}

Phillips (1985) aponta seis categorias de aprendizagem por meio das quais um usuário pode se envolver com um computador: jogo, questionário, construção e reconstrução de texto, resolução de problemas e exploração. Destacam-se nos apps duas dessas categorias: questionário e reconstrução de texto. Nas atividades relacionadas a questionários, os usuários desenvolvem a gramática, o vocabulário e a pronúncia, de forma automática, por meio de estímulo-resposta. Quanto à reconstrução de texto, surgem atividades de múltipla escolha e equivalência, para relacionar imagens com vocabulário e tradução correta ou ordenar a tradução de sentenças, também por meio de estímulo-resposta e repetição.

\subsubsection{Abordagem pedagógica: concepções da linguagem}

Os três aplicativos testados têm um sistema fechado de "repetição e prática", com pouca ou nenhuma oportunidade para o aprendiz estabelecer relações afetivas e sociais (SCHUMANN, 1978), utilizar inputs (KRASHEN, 1985) ou interagir (HATCH, 1978; LONG, 1996). Em sua maioria, as questões são fechadas, com pouca flexibilidade. Embora as tarefas fechadas desempenhem um importante papel em situações rotineiras de aprendizagem, sua prevalência vai contra os princípios do interacionismo.

12 Informação coletada no site do Babbel no dia 18 de setembro de 2019. 
Atividades de múltipla escolha, preenchimento de lacunas, escolha de certo ou errado, correspondência, classificação, caça-palavras ou escrita de frases sugerem padrões comumente atribuídos à aprendizagem por condicionamento (behaviorismo). Se nas ferramentas analisadas ocorrem interações, essas são reservadas apenas aos módulos pagos. O Quadro 1 demonstra o que a análise dos apps nos permitiu diagnosticar em termos de linguagem.

Quadro 1 - Análise dos apps

\begin{tabular}{|c|c|c|c|}
\hline & DUOLINGO & BABBEL & BUSUU \\
\hline $\begin{array}{c}\text { Ensino da } \\
\text { língua }\end{array}$ & $\begin{array}{l}\text { Behaviorismo, com tenta- } \\
\text { tivas de construtivismo e } \\
\text { interacionismo. } \\
\text { Ênfase na ortografia, com } \\
\text { pouca contextualização das } \\
\text { palavras ensinadas. }\end{array}$ & $\begin{array}{l}\text { Behaviorismo, com tenta- } \\
\text { tivas de construtivismo e } \\
\text { interacionismo. } \\
\text { Reprodução da escrita pela } \\
\text { audição de algumas pala- } \\
\text { vras e pequenos textos. }\end{array}$ & $\begin{array}{l}\text { Behaviorismo, com tenta- } \\
\text { tivas de construtivismo e } \\
\quad \text { interacionismo. } \\
\text { Reprodução da escrita pela } \\
\text { audição de algumas pala- } \\
\text { vras e pequenos textos. }\end{array}$ \\
\hline Tarefas & $\begin{array}{c}\text { Atividades de múltipla } \\
\text { escolha, preenchimento de } \\
\text { lacunas, escolha de certo } \\
\text { ou errado, correspondência, } \\
\text { classificação, caça-palavras } \\
\text { ou escrita de frases. } \\
\text { Ênfase na ortografia, com } \\
\text { pouca contextualização das } \\
\text { palavras ensinadas. }\end{array}$ & $\begin{array}{c}\text { Atividades de múltipla } \\
\text { escolha, preenchimento de } \\
\text { lacunas, escolha de certo } \\
\text { ou errado, correspondência, } \\
\text { classificação, caça-palavras } \\
\text { ou escrita de frases. } \\
\text { Reprodução da escrita pela } \\
\text { audição de algumas pala- } \\
\text { vras e pequenos textos. }\end{array}$ & $\begin{array}{c}\text { Atividades de múltipla } \\
\text { escolha, preenchimento de } \\
\text { lacunas, escolha de certo } \\
\text { ou errado, correspondência, } \\
\text { classificação, caça-palavras } \\
\text { ou escrita de frases. } \\
\text { Reprodução da escrita pela } \\
\text { audição de algumas pala- } \\
\text { vras e pequenos textos. }\end{array}$ \\
\hline Propósito & $\begin{array}{c}\text { Permite verificar a própria } \\
\text { evolução e seguir outros } \\
\text { usuários. }\end{array}$ & $\begin{array}{l}\text { Oferece espaço de colabo- } \\
\text { ração com outras pessoas } \\
\text { para formação de grupos. No } \\
\text { entanto, essa escolha é paga. }\end{array}$ & $\begin{array}{c}\text { Segue o formato de rede } \\
\text { social, possibilitando aos } \\
\text { usuários interagir e corrigir } \\
\text { os trabalhos uns dos outros. }\end{array}$ \\
\hline
\end{tabular}

Fonte: Elaboração do autor baseado nos sites dos aplicativos.

Na visão de língua e aprendizagem dos apps, destaca-se a fragmentação do idioma em palavras e frases, o que dificulta a contextualização diária, uma vez que o foco está em falar sobre a lingua, e não em abordar situações de uso. Os três aplicativos deixam transparecer uma concepção de educação reprodutora, e este talvez seja o motivo da dificuldade de muitos profissionais em compreender como experiências virtuais de aprendizagem de idiomas podem enriquecer o ensino e ser utilizadas em sala de aula (MARÇAL, 2000).
Os três aplicativos têm estrutura simples e diversificada, com atividades classificadas segundo afinidade semântica. As palavras são acompanhadas de imagens que contextualizam o que se deseja apresentar pela escrita e leitura. A pronúncia é bem nítida, sem ruídos, assim como as imagens não geram dúvidas sobre o significado da palavra apresentada. Em situações que podem gerar dúvidas, o app faz observações sobre o contexto, como no exemplo da Figura 4. 
Figura 4 - Particularidades dos países de língua portuguesa

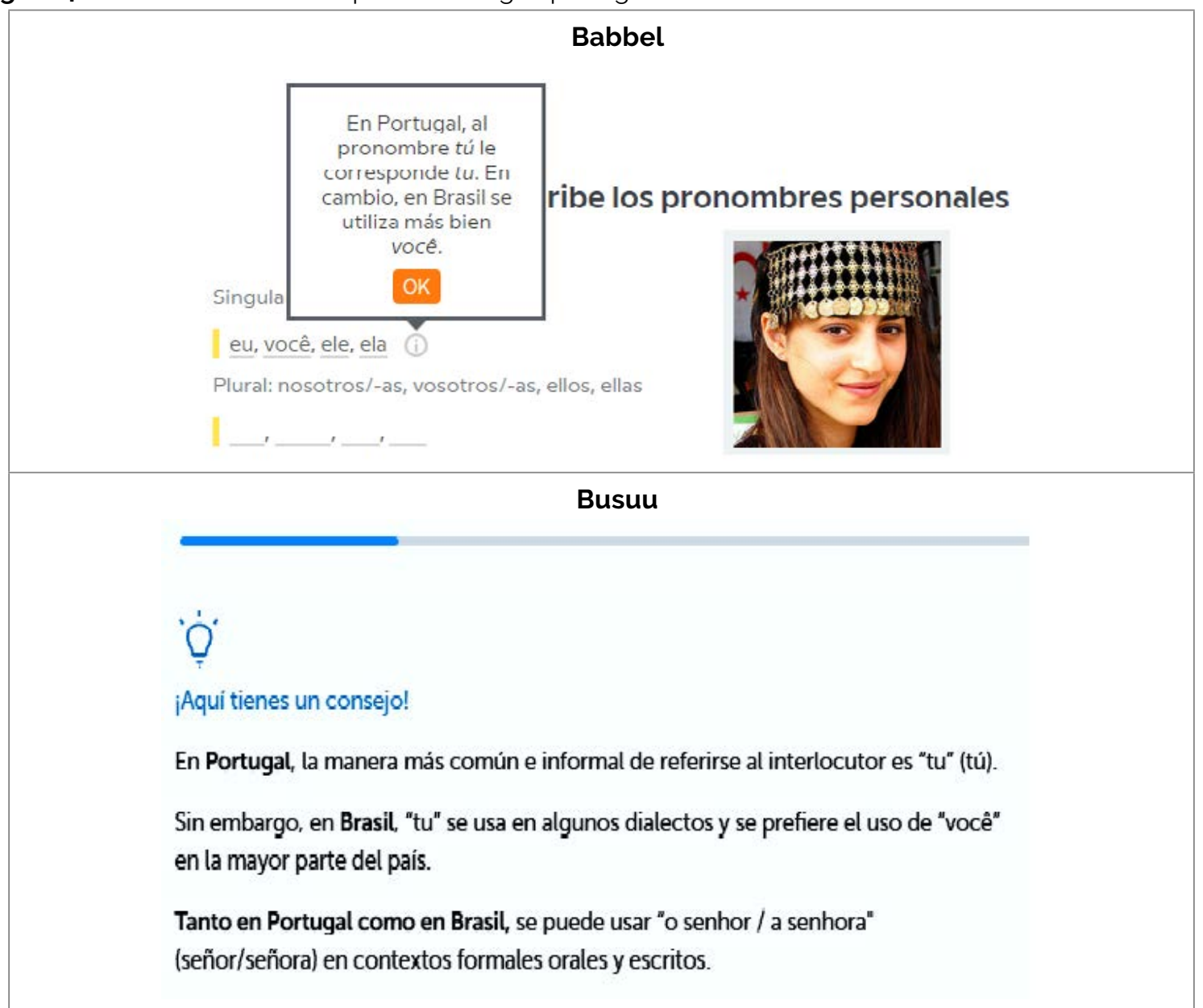

Fonte: Site dos aplicativos Babel e Busuu.

Os apps chamam atenção para as diferenças na forma de tratamento no Brasil e em Portugal. No entanto, em geral, a perspectiva comunicativa está focada no vocabulário ou em frases que não refletem totalmente as variações de significado. As ferramentas são muito sensiveis a erros, e as respostas desejadas nas atividades de tradução não estão abertas a outras possibilidades.

\subsubsection{Conteúdo abordado}

A maioria dos conteúdos abordados se concentra em habilidades usadas de forma passiva, ou seja, a aquisição de vocabulário, a escrita, a pronún- cia e os termos gramaticais são apresentados de modo simplificado, sem prática oral ou estratégias de interação com esforços comunicativos (PAIVA, 2014). Diálogos, ditados e correspondências são táticas de compreensão auditiva encontradas nos três aplicativos. O desenvolvimento do vocabulário destaca temas comuns, com uma compreensão substancial de escuta, acompanhada de inputs orais simples. As tarefas, nas quais o usuário poderia ir além de palavras isoladas, comunicando pensamentos e ideias completas, não se destacam nos apps. Os conteúdos abordados são resumidos no Quadro 2 a seguir. 
Quadro 2 - Temas abordados nos aplicativos

\begin{tabular}{|c|c|c|}
\hline DUOLINGO & BABBEL & BUSUU \\
\hline $\begin{array}{l}\text { Saudações, comida, animais, } \\
\text { roupas, cores, perguntas, } \\
\text { datas, familia, profissão, luga- } \\
\text { res, objetos, gente, viagens, } \\
\text { números, educação, natureza, } \\
\text { esportes, artes, comunicação, } \\
\text { medicina, politica, ciência, } \\
\text { negócios, eventos, atributos, } \\
\text { regras gramaticais. }\end{array}$ & $\begin{array}{l}\text { Profissões, situações diárias, } \\
\text { férias, lazer, compras, gos- } \\
\text { tos musicais, como lidar com } \\
\text { bancos, planejar festas, trans- } \\
\text { porte, mundo digital, estado } \\
\text { de saúde, teatro, experiências } \\
\text { na faculdade, poluição am- } \\
\text { biental, lição de casa, regras } \\
\text { gramaticais, gente e cultura, } \\
\text { trava-línguas, modismos, falsos } \\
\text { cognatos. }\end{array}$ & $\begin{array}{l}\text { Cumprimentos, sentimentos, ami- } \\
\text { gos, cidades, pessoas e locais de } \\
\text { trabalho, cidade do usuário, familia, } \\
\text { cotidiano, planos culturais, comida, } \\
\text { casa, mobiliário, rotinas, datas e } \\
\text { números, passatempos, horários e } \\
\text { meios de transporte, esporte, per- } \\
\text { sonalidade, final de semana, roupas, } \\
\text { compras, corpo, doenças, rotinas, } \\
\text { turismo, vida saudável, planos com } \\
\text { amigos, tempo, religião, informações } \\
\text { pessoais, escola, eventos da vida, } \\
\text { férias, passatempos, jantar, tarefas } \\
\text { domésticas, regras gramaticais. }\end{array}$ \\
\hline
\end{tabular}

Fonte: Sites dos aplicativos.

O Duolingo oferece cursos com graus de dificuldade conforme nivel de proficiência do usuário. O app se baseia no QCER e abrange os níveis A1, A2, B1 e B2, com divisão em temas e tópicos gramaticais. Desenvolvidas em etapas, como em um vídeo game, as tarefas são desbloqueadas à medida em que os objetivos vão sendo cumpridos. Há atalhos ou testes de aptidão que permitem ao usuário avançar etapas. Ao término de cada unidade, dividida em nível básico, médio e avançado, o usuário recebe um relatório de desempenho. Embora ele incentive os aprendizes a testar suas habilidades, a ênfase está na tradução e compreensão auditiva de palavras e frases.

O app Babbel, também baseado no QCER, oferece atividades relacionadas ao padrão internacional de competências linguísticas nos níveis $A_{1}, A_{2}$ e $B 1$, com cursos para o ensino de português subdivididos em seis blocos. Como nos propusemos a analisar somente o conteúdo gratuito, ficamos limitados às lições mais simples. No módulo "Curso para Iniciantes 1", são apresentadas quatro atividades. A primeira consiste em escutar e repetir palavras e expressões. Apresenta-se um flashcard com uma foto e palavra ou expressão correspondente na língua do usuário, com tradução para o português. Caso a opção de reconhecimento de voz tenha sido autorizada, o usuário repete o conteúdo e o aplicativo informa se a pronúncia está correta ou não; caso não tenha sido autorizado, há apenas a leitura pelo aplicativo.

Na segunda atividade, as palavras surgem com as letras embaralhadas e o usuário deve escrevê-las corretamente. Em algumas expressões, aparece um balão explicativo diferenciando a ortografia ou o uso em Portugal ou Brasil, como no caso do pronome "você" ou variações como "tudo bem" e "tudo bom". Na terceira atividade, o usuário constrói frases, completando um diálogo com palavras ou termos em português utilizados anteriormente. Abaixo, o texto a ser completado aparece na língua materna do usuário.

Por fim, na quarta atividade, o usuário deve arrastar palavras. Frases incompletas são apresentadas e, para completá-las, pode-se usar o teclado ou clicar sobre as letras. Assim que o módulo é finalizado, o aplicativo apresenta a pontuação obtida e a opção de seguir com o curso na versão paga. A mensagem com a pontuação obtida traz um incentivo para que o aprendiz siga com as aulas, conforme aponta a Figura 5 a seguir. 
Figura 5 - Incentivo ao estudo

\section{监 \\ Fantástico, Josiane Cani!}

Respuestas correctas

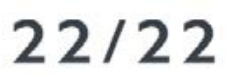

¡Sigue asi! Accede a todos los cursos y lecciones-

\section{Accodo al contonido do portugueds}

Fonte: Site do aplicativo Babbel.

O app Busuu também se baseia no QCER, abrangendo os niveis $\mathrm{A} 1, \mathrm{~A} 2, \mathrm{~B} 1$ e $\mathrm{B} 2$, divididos em Principiante, Elementar, Intermediário, Intermediário Alto e Curso de Viagem. O nível Principiante (A1 do QCER) traz 24 lições, o Elementar (A2 do QCER), com 16 lições, o Intermediário (B1 do QCER), com 19 lições e o Intermediário Alto
(B2 do QCER) divide-se em 15 lições. Por fim, o Curso de Viagem, com apenas 4 lições, aborda expressões úteis para viagem, como se locomover, perguntas importantes e turismo.

Além de cursar esses niveis, o usuário pode se comunicar com falantes nativos por meio de chat em vídeo, de modo a estabelecer uma troca com outros aprendizes, gravando falas e recebendo feedbacks.

\subsubsection{Linguagem visual}

Elementos visuais estimulam o interesse de quem está aprendendo uma outra língua. Associar a imagem a um conceito auxilia o aprendizado. A figura de uma casa conectada a seu nome, house, fundamenta o significado de um novo vocábulo com ideias concretas. O design não é apenas uma referência visual, pois vai além do código linguístico e é ele mesmo uma mensagem. No entanto, nos aplicativos analisados, as imagens são mais figurativas do que cognitivas, conforme mostrado na Figura 6.

Figura 6 - Imagens dos aplicativos

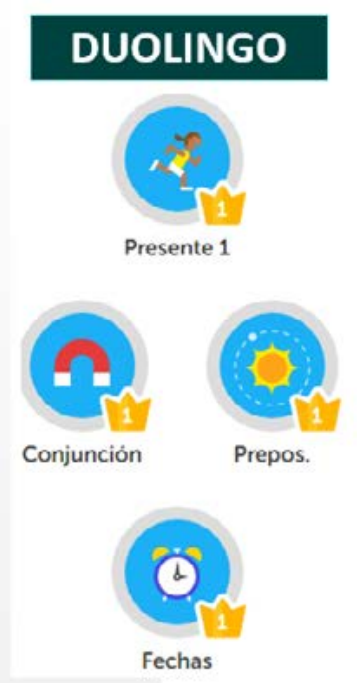

Fonte: Site dos aplicativos.

Observamos, por exemplo, que a figura escolhida para introduzir as estações climáticas não representa nenhum país de língua portuguesa. A foto retrata uma paisagem da Grécia. O site, no entanto, poderia usar imagens de países lusófonos para incentivar conhecimentos sobre cultura, clima e economia, dentre outros. Essa também seria uma oportunidade de comparar vocábulos e expressões de mesmo significado e diferentes significantes por meio de imagens, como na Figura 7. 
Figura 7 - Vocábulos diferentes com os mesmos significados

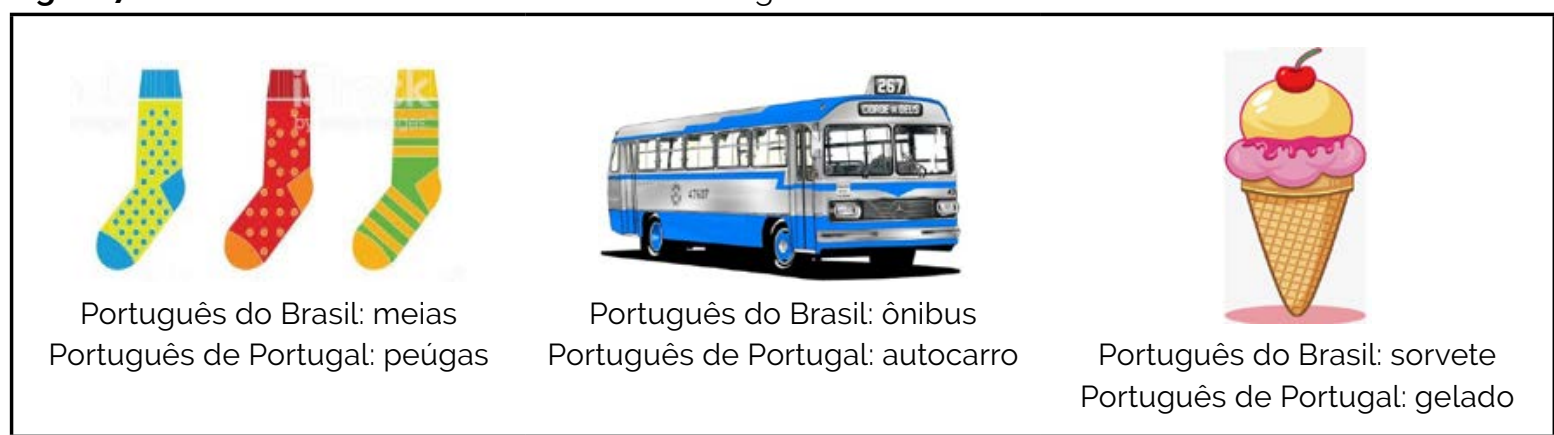

Fonte: Adaptado de imagens do site Pinterest (https://br.pinterest.com/2020).

O que pudemos diagnosticar na análise dos apps quanto à linguagem visual é resumido no Quadro 3.

Quadro 3 - Apresentação de imagens dos aplicativos

\begin{tabular}{|c|c|c|}
\hline DUOLINGO & BABBEL & BUSUU \\
\hline Figuras extraidas de bancos de imagens, deixando os aspectos culturais fora do contexto de comunicação. \\
\hline Apresenta um design infantil. & Ilustra as situações com fotos. & Ilustra as situações com fotos. \\
\hline
\end{tabular}

Fonte: Elaboração do autor baseado nos sites dos aplicativos.

A análise final, comparada dos apps, é sintetizada no Quadro 4.

Quadro 4 - Comparativo entre os jogos

\begin{tabular}{|l|c|c|c|}
\hline & Duolingo & Babbel & Busuu \\
\hline $\begin{array}{l}\text { Teorias de } \\
\text { aprendizagem }\end{array}$ & $\begin{array}{c}\text { Behaviorismo, com tenta- } \\
\text { tivas de construtivismo e } \\
\text { interacionismo }\end{array}$ & $\begin{array}{c}\text { Behaviorismo, com tenta- } \\
\text { tivas de construtivismo e } \\
\text { interacionismo }\end{array}$ & $\begin{array}{c}\text { Behaviorismo, com tenta- } \\
\text { tivas de construtivismo e } \\
\text { interacionismo }\end{array}$ \\
\hline $\begin{array}{l}\text { Concepção de } \\
\text { linguagem }\end{array}$ & $\begin{array}{c}\text { Instrumento de } \\
\text { comunicação }\end{array}$ & $\begin{array}{c}\text { Instrumento de } \\
\text { comunicação }\end{array}$ & $\begin{array}{c}\text { Instrumento de } \\
\text { comunicação }\end{array}$ \\
\hline Conteúdo abordado & $\begin{array}{c}\text { Destaque para } \\
\text { o vocabulário }\end{array}$ & $\begin{array}{c}\text { Destaque para } \\
\text { o vocabulário }\end{array}$ & $\begin{array}{c}\text { Destaque para } \\
\text { o vocabulário }\end{array}$ \\
\hline Linguagem visual & $\begin{array}{c}\text { Bancos de imagens que } \\
\text { nalustram os aspectos } \\
\text { culturais abordados. } \\
\text { Design infantil. }\end{array}$ & $\begin{array}{c}\text { Bancos de imagens que } \\
\text { nalustram os aspectos } \\
\text { culturais abordados. } \\
\text { Fotos. }\end{array}$ & $\begin{array}{c}\text { Bancos de imagens que } \\
\text { náo ilustram os aspectos } \\
\text { culturais abordados. } \\
\text { Fotos. }\end{array}$ \\
\hline
\end{tabular}

Fonte: Elaboração do autor baseado nos sites dos aplicativos.

Admitimos que a necessidade de motivação, treino e repetição para a aprendizagem se faz necessária. No entanto, se o idioma for apresentado apenas como um código por meio de exercícios estruturais de vocabulário e tópicos gramaticais, escrita e leitura descontextualizada, o usuário nunca irá se deparar com conflitos constantes na realidade de uma língua. 
Atividades mais interativas ajudariam o usuário a atuar fora do ambiente restrito do dispositivo móvel. A integração de propostas que se aproximam da realidade dos países lusófonos favoreceria a aquisição da língua, considerando que o usuário adentra à cultura, ao espaço geográfico, a costumes, à religião e à natureza de países que queira visitar, seja por motivos profissionais ou de lazer.

Um fato que merece ser considerado é que a função complementar desses aplicativos permite autonomia e uso em momentos disponiveis do aprendiz/usuário. A utilização dos aplicativos tem efeitos positivos, como a possibilidade de escolher quando e onde estudar, o desenvolvimento da autonomia do usuário, a diminuição da distância entre aprendizagem formal e informal e a ampliação do vocabulário.

Além disso, embora não se aproxime da realidade de todos os países lusófonos, a linguagem visual dos três aplicativos analisados incentiva o usuário a praticar o idioma. Assim, apropriar-se dessas ferramentas pode gerar novas formas de apender.

\section{Conclusões}

O estudo se propôs a analisar o uso de dispositivos móveis para auxiliar a aprendizagem de língua portuguesa por estrangeiros. Nossa principal conclusão diz respeito à potencialidade dos conteúdos trabalhados, que acaba sendo prejudicada pela descontextualização da maioria das tarefas, que não consideram, inclusive, a variedade dos países lusófonos: Guiné-Bissau, Angola, Cabo Verde, Moçambique, Timor-Leste, São Tomé e Príncipe e Guiné Equatorial, com destaques para a língua falada no Brasil e em Portugal.

Duolingo, Babbel e Busuu priorizam o conhecimento explícito, quase sempre desprovido de sentido em um contexto real. O uso de metodologias, como a behaviorista, sem adaptar suas contribuições às possibilidades das novas tecnologias, restringe a interação a estruturas rigidas e reduzidas, pouco contribuindo para a autonomia linguística.

A avaliação não pretende desconsiderar o uso desses aplicativos como ferramenta de aprendizado de línguas. A instrução dada aos usuários é essencial para a aquisição da linguagem e, mesmo que limitados, esses apps podem ser utilizados, inclusive em tarefas na sala de aula. Não como substitutos do professor, considerando que estão muito longe, ainda, de substituirem o professor de LA, mas como instrumento para motivar os alunos a estudar além da escola.

Apesar do predomínio da estrutura behaviorista, que trabalha a lingua de forma fragmentada, como objeto de estudo e não como forma de comunicação e interação social, as ferramentas apresentam um sistema bem planejado em termos de gamificação. Assim, a análise dos dados permite concluir que os três aplicativos contribuem mais como suporte de aprendizagem do que como plataforma de ensino propriamente dito.

As profundas e intensas mudanças ocorridas na sociedade do conhecimento, associadas ao universo tecnológico, tornam o aprendizado um processo cada vez mais social, e organizações e grupos com os quais convivemos diariamente são fundamentais para o ensino. Nesse sentido, os aplicativos são potenciais ferramentas para redimensionar o contato com pessoas de diferentes culturas e lugares, possibilitando uma aprendizagem interativa.

\section{Referências}

ALMEIDA FILHO, J. C. P. Dimensões comunicativas no ensino de linguas. Campinas: Pontes, 1993

BLAKE, R. J. Brave new digital classroom: technology and foreign language learning. Washington, DC: Georgetown University Press, 2013.

BRASIL. Brasil. Instituto Nacional de Estudos e Pesquisas Anisio Teixeira. Documento base do exame Celpe-Bras [recurso eletrônico]. - Brasília: Instituto Nacional de Estudos e Pesquisas Educacionais Anísio Teixeira, 2020. Acesso em: 13 nov. 2020.

CANI, J. B.; SANTIAGO, M. E. V. O papel do quadro comum europeu de referência para idiomas: aprendizagem, ensino e avaliação (QCER) na internacionalização das IES: uma análise sob a perspectiva do Letramento Crítico e dos Multiletramentos. Trabalhos em Linguistica Aplicada, Campinas, v. 57, n. 2, p. 1164-1188, 2018. https://doi.org/10.1590/010318138650002297941

CHEON, J.; LEE, S.; CROOKS, S. M.; SONG, J. An investigation of mobile learning readiness in higher education based on the theory of planned behavior. Computers \& Education, Amsterdam, v. 59, n. 3. p. 1054-1064, 2012. Disponivel em: https://www.sciencedirect.com/science/ article/abs/pii/S0360131512000991. Acesso em: 26 ago. 2018. https://doi.org/10.1016/j.compedu.2012.04.015 
CONSELHO DA EUROPA. Quadro europeu comum de referência para as linguas: aprendizagem, ensino, avaliação. Porto: Edições Asa, 2001. Disponivel em: http:// area.dge.mec.pt/gramatica/Quadro_Europeu_total. pdf. Acesso em: 1 jul. 2018

CORREA, L. M. S. Aquisição da linguagem: uma retrospectiva dos últimos trinta anos. DELTA, São Paulo, v. 15. p. 339-83, 1999.

COSTA, Giselda Santos. Mobile learning e zona de desenvolvimento proximal: transformando o ensino e aprendizagem de línguas através da tecnologia móvel. Polifonia, Cuiabá, v. 25, n. 37.2, p. 206-220, 2018.

DELEUZE, G.; GUATTARI, F. Mil platôs: capitalismo e esquizofrenia. Rio de Janeiro: Editora 34, 1996.

DOUGLAS, D. Assessing languages for specific purposes. Cambridge: Cambridge University Press, 2000.

FIDRMUC, J.; FIDRMUC, J. Foreign languages and trade: evidence from a natural experiment. Empirical Economics, Vienna, n. 50, p. 31-49, 2016. https://doi. org/10.1007/s00181-015-0999-7

GRUBA, P. Computer Assisted Language Learning (CALL). In: DAVIES, A.; ELDER, C. (ed.). The handbook of applied linguistics. Oxford: Blackwell Publishing, 2004. p. 623-648.

$\mathrm{HATCH}$, E. Second language acquisition. Rowley, MA: Newbury House, 1978.

HEALEY, D.; JOHNSON, N. TESOL CALL Interest Section Software List. Alexandria, VA: TESOL, 1995.

JOHNSON, M. A philosophy of second language acquisition. New Haven: Yale University Press, 2004

KRASHEN, S. The input hypothesis: issues and implications. New York: Longman, 1985.

LARSEN-FREEMAN, D.; CAMERON, L. Complex systems and applied linguistics. Oxford: Oxford University Press, 2008.

LEFFA, V. J. Metodologia do ensino de línguas. In: $\mathrm{BOHN}$, H. I.; VANDRESEN, P. (org.). Tópicos em linguística aplicada: o ensino de línguas estrangeiras. Florianópolis: Editora da UFSC, 1988. p. 211-236.

LÉVY, P. O que é virtual? São Paulo: Editora 34, 1996.

LONG, M. The role of the linguistic environment in second language acquisition. In: RITCHIE, W:; BHATIA, T. (ed.). Handbook of second language acquisition. San Diego: Academic Press, 1996. p. 413-468.

MARÇAL, J. C. Novas tecnologias da informação e comunicação no contexto da formação continuada à distância. Perspectivas em Ciência da Informação, Belo Horizonte, v. 5, n. 2, p. 267-273, 2000. Disponivel em: http://portaldeperiodicos.eci.ufmg.br/index.php/pci/ article/viewFile/129/327.html. Acesso em: 29 ago. 2018.

MITCHELL, R.; MARSDEN, E.; MYLES, F. Second language learning theories. Abingdon: Routledge, 2013.
MOTA, B. C. C. et al. Duolingo: inovação do inglês na escola. Revista do Plano Nacional de Formação de Professores da Educação Básica, Teresina, v. 4, n. 1, p. 142-147, 2016

MUNDAY, P. The case for using DUOLINGO as part of the language classroom experience. Revista lberoamericana de Educación a Distancia, Madrid, v. 19, n. 1, p. 83-101, 2016. https://doi.org/10.5944/ried.19.1.14581

OLIVEIRA, G. M. de. O lugar das línguas: a América do Sul e os mercados linguísticos na Nova Economia. Synergies Brésil, São Paulo, n. 1, p. 21-30, 2010.

PAIVA, Vera Lúcia Menezes de Oliveira. A wwww e o ensino de Inglês. Revista Brasileira de Linguistica Aplicada, v. 1, n. 1, p. 93-116, 2001. https://doi.org/10.1590/ $\underline{\mathrm{S} 1984-63982001000100006}$

PAIVA, V. L. M. de O. Aquisição de segunda lingua. São Paulo: Parábola, 2014.

PHILLIPS, M. Logical possibilities and classroom scenarios for the development of CALL. In: BRUMFIT, C: PHILLIPS, M.; SKEHAN, P. (ed.). Computers in English language teaching. New York: Pergamon, 1985. p. 25-46.

PROTALINSKI, E. Hyperloop's intro video claims the future is now. Dated Sep, v. 17, p. 5, 2015

SACCOLA.; SCHLEMMER E.; BARBOSA, J. M-learning e u-learning: novas perspectivas da aprendizagem móvel e ubíqua. São Paulo: Pearson, 2011.

SCARAMUCCI, M. V. R. O projeto Celpe-Bras no âmbito do Mercosul: contribuições para uma definição de proficiência comunicativa. In: ALMEIDA FILHO, J. C. P. (org.). Português para estrangeiros: interface com o espanhol. Campinas: Pontes, 1995. p. 77-90.

SHARMA, S. K.; KITCHENS, F. L.; BOOKER, Q. E.; XU, H Web services model for mobile, distance and distributed learning using service-oriented architecture. International Journal of Mobile Communications, Geneva, v. 4, n. 2, p. 178-192, 2006. https://doi.org/10.1504/ IJMC.2006.008608

STERN, H. H. Linguistic theory and language teaching: emergence of a relationship. In: STERN, H. Fundamental concepts of language teaching. Oxford: Oxford University Press, 1987. p. 152-187.

SCHUMANN, John H. O relacionamento de pidginização, criação e descreolização para a segunda aquisição de língua 1. Aprendizagem de línguas, v. 28, n. 2, p. 367-379, 1978.

TRAXLER, J. Defining, discussing and evaluating mobile learning: the moving finger writes and having writ... The International Review of Research in Open and Distance Learning. Athabasca, v. 8, n. 2, 2007. Disponivel em: http://www.irrodl.org/index.php/irrodl/ article/view/346. Acesso em: 22 ago. 2018. https:// doi.org/10.19173/irrodl.v8i2.346

TRAXLER, J.; KUKULSKA-HULME, A. (ed.). Mobile learning: a handbook for educators and trainers. London: Routledge, 2005 
UNESCO. Diretrizes de politicas para a aprendizagem móvel. Brasilia, DF: Organização das Nações Unidas para a Educação, 2013. Disponivel em: http://unesdoc. unesco.org/images/0022/002277/227770por.pdf. Acesso em: 27 ago. 2018.

WANG, Y-S.; WU, M.-C.; WANG, H.-Y. Investigating the determinants and age and gender differences in the acceptance of mobile learning. British Journal of Educational Technology, Hoboken, v. 40, n. 1, p. 92-118, 2009. https://doi.org/10.1111/j.1467-8535.2007.00809.x

WARSCHAUER, M. Computer assisted language learning: an introduction. In: FOTOS, S. (ed.). Multimedia language teaching. Tokyo: Logos International, 1996. p. 3-20.

WARSCHAUER, M.; HEALEY, D. Computers and language learning: an overview. Language Teaching, Cambridge, v. 31, n. 2, p. 57-71, 1998. https://doi.org/10.1017/ $\underline{\text { So261444800012970 }}$

WEIGLE, S. C. Assessing writing. Cambridge: Cambridge University Press, 2002.

\section{Josiane Brunetti Cani}

Doutora em Linguistica Aplicada, servidora do Instituto Federal de Educação, Ciência e Tecnologia do Espírito Santo (Ifes) e professora da Faculdade Castelo Branco. Lider do grupo de pesquisa "Linguagens e Tecnologias", do Ifes, e membro do grupo "Texto: semiótica e tecnologia livre", da UFMG, com interesse em questões relacionadas a linguagens, tecnologias digitais, ensino de Língua Portuguesa e formação de professores.

\section{Endereço para correspondência}

Josiane Brunetti Cani

Instituto Federal de Educação, Ciência e Tecnologia do Espírito Santo (Ifes)

Av. Rio Branco, 50 - Santa Lucia

Vitória - ES, 29056-264 